\title{
Caracterização tecnológica de sobremesas lácteas achocolatadas cremosas elaboradas com concentrado protéico de soro e misturas de gomas carragena e guar
}

\author{
Patrícia Hideko Lemos Nikaedo, Florence Franco Amaral, Ana Lúcia Barretto Penna*
}

Departamento de Engenharia e Tecnologia de Alimentos, Instituto de Biociências, Letras e Ciências Exatas, Universidade Paulista Júlio de Mesquita Filho - UNESP, Campus de São José do Rio Preto - SP

*Correspondência:

A.L.B. Penna

Rua Cristóvão Colombo, 2265

15054-000 - São José do Rio Preto -SP

E-mail: analucia@eta.ibilce.unesp.br
O consumo de sobremesas lácteas tem apresentado importante crescimento nesta última década, justificado pelo progresso tecnológico em ingredientes e processos. Neste trabalho efetuouse a caracterização físico-química e sensorial de sobremesas lácteas achocolatadas cremosas, nas quais o concentrado protéico de soro - CPS (3,0; 2,0 e 1,0\%) foi usado com o leite em pó integral (5,0; $6,0$ e $7,0 \%)$, carragena $(0,05 ; 0,15$ e $0,25 \%)$, goma guar $(0,25$; 0,15 e 0,05\%), chocolate em pó (2,8\%), açúcar (11,5\%) e sorbato de potássio $(0,08 \%)$. Os resultados mostram que é viável utilizar o CPS em substituição ao leite em pó, oferecendo um produto com menores teores de gordura e de sólidos totais, e maior teor de proteinas. O produto apresentou melhor qualidade nutricional, além da redução calórica, favorecendo seu consumo por pessoas preocupadas com a saúde. A sobremesa elaborada com 1,00\% de CPS, 7,00\% de leite em pó, 0,05\% de carragena e 0,25\% de goma guar foi considerada a melhor pelos provadores, com aceitabilidade acima do valor 4 (bom).
Unitermos:

- Sobremesas lácteas

- Concentrado protéico de soro

- Carragena

- Guar

- Produtos lácteos.

\section{INTRODUÇÃO}

As sobremesas lácteas prontas para comer, com vida de prateleira média, apresentaram importante crescimento nas últimas décadas. Os ingredientes inovadores e os sistemas tecnológicos aplicados nas fábricas de laticínios têm proporcionado novas alternativas às sobremesas lácteas clássicas feitas em casa, permitindo a produção de sobremesas com novos sabores, com maior digestibilidade e maior valor nutritivo.

Estes produtos são basicamente constituídos por: leite, amido, açúcar, flavorizantes, estabilizantes, emulsificantes, geleificantes, espessantes, corantes, aromatizantes, ovos, polpas de frutas ou chocolate e conservantes, com formulações variáveis em função das combinações dos ingredientes utilizados. De maneira geral, estes produtos são complexos cuja estabilidade depende muito da tecnologia de fabricação, das características intrínsecas de cada produto e da estocagem sob condições refrigeradas (Nunes et al.,1998).

As condições de processamento têm importância vital na preparação das sobremesas achocolatadas e de- 
vem ser estabelecidas conforme a formulação e o tipo de leite. O processo de fabricação é constituído basicamente das etapas de preparo da mistura, tratamento térmico, homogeneização, resfriamento parcial e estocagem sob refrigeração (Freitas, s.d.).

Vários tratamentos térmicos podem ser aplicados: pasteurização ou esterilização, tanto com o uso de autoclave rotativa quanto pelo processo de ultra-alta temperatura UAT $\left(130-150{ }^{\circ} \mathrm{C}\right)$ por curto tempo (alguns segundos). O objetivo de tais tratamentos térmicos, independentemente de garantir a segurança do produto, é prolongar a vida-de-prateleira das sobremesas lácteas por redução e destruição de microrganismos e por inativação de enzimas e, ao mesmo tempo, conservando as propriedades sensoriais e o valor nutricional tanto quanto possível.

O tratamento térmico desnatura as proteínas, tornando-as menos solúveis, o que promove a formação de uma rede estável, porém, a desnaturação excessiva pode produzir coágulos. Além disso, para impedir a sedimentação é preciso manter baixa a temperatura durante o processo de envase asséptico (Van Oorschot, 2001).

$\mathrm{O}$ acondicionamento a quente $\left(68-75^{\circ} \mathrm{C}\right)$ visa aproveitar a fluidez do alimento, além de ser uma garantia microbiológica, uma vez que o produto final apresenta $\mathrm{pH}$ entre 6,2 e 6,5. A cobertura, quando presente, pode ser colocada na embalagem antes ou após ter sido dosado o produto. Sobremesas refrigeradas aeradas são acondicionadas na embalagem à temperatura ambiente $\mathrm{e}$, portanto, requerem boas condições higiênico-sanitárias durante o envase para não haver contaminação do produto (Alves et al., 1994).

As características de tamanho das partículas e densidade, estrutura interna, cor e aroma dos ingredientes podem potencialmente influenciar as condições necessárias para o processamento, as propriedades físicas dos produtos achocolatados e/ou as características sensoriais do produto final. $\mathrm{O}$ tamanho das partículas do chocolate ocupa importante papel na produção da viscosidade. Se as partículas são muito pequenas, a viscosidade é alta e mais gordura é necessária para cobrir estas finas partículas para reduzir a viscosidade. O leite em pó feito com partículas que quebram facilmente em partículas muito pequenas sofrem deste problema (Liang, Hartel, 2004).

Nos últimos anos, tem-se notado a tendência à substituição do leite pelo soro, na fabricação dos mais diversos produtos, tanto por questões econômicas, quanto por vantagens qualitativas proporcionadas pela utilização do soro, tais como melhoria nas qualidades gustativas e na textura, emulsificação, estabilidade, na dispersibilidade em misturas secas, na ação anti-aglutinante, no aumento do potencial nutritivo e na maior vida-de-prateleira (Lagrange, Dallas, 1997).
As frações do soro podem ser agrupadas em sete categorias básicas, de acordo com as características determinadas pelo tipo e grau de processamento aos quais são submetidas. São elas: soro doce em pó, soro ácido em pó, soro com teor de lactose reduzido, soro desmineralizado, concentrados protéicos de soro (CPS), isolados protéicos de soro (IPS) e lactose. Cada um desses produtos de soro é utilizado com base nas características funcionais específicas apresentadas por cada um deles.

O soro doce em pó é um importante subproduto da indústria de fabricação de queijos. Devido às suas numerosas propriedades funcionais, como agente de escurecimento e de volume, formador de espuma e pela capacidade de retenção de água, o soro doce em pó é utilizado em uma variedade de indústrias de alimentos. Os concentrados protéicos de soro são também conhecidos pelas aplicações devido à variável funcionalidade e aroma (Banavara, Anupama, Rankin, 2003).

Um dos tipos de concentrado protéico de soro possui $34-36 \%$ de proteínas, $48-52 \%$ de lactose, $3-4,5 \%$ de gordura, $6,5-8 \%$ de cinzas, $3-4,5 \%$ de umidade. Ele é obtido pela remoção de quantidade suficiente de constituintes não protéicos de soro pasteurizado e é fabricado por meio de técnicas de separação física, tais como precipitação, filtração ou diálise. Este concentrado pode ser usado em produtos lácteos, de panificação, de confeitaria tais como "snacks" e salgadinhos, produtos nutricionais como fonte econômica de sólidos lácteos, como substituinte parcial do leite em pó desnatado e como proteínas solúveis em soluções ácidas (USDEC, 1997).

Para manter as partículas do pó de cacau em suspensão é preciso viscosidade relativamente alta (Van Oorschot, 2001). A finalidade do uso de gomas é melhorar e manter as características reológicas, tais como a textura, a viscosidade, a consistência, o aspecto e o corpo, tão importantes quanto as sensoriais, como o sabor e o aroma do produto. A ação dessas substâncias inclui basicamente a retenção de água e o aumento da viscosidade (Dziezak, 1991). Em produtos lácteos achocolatados, as gomas reagem com as proteínas do leite e as partículas do cacau a fim de formar rede tridimensional, que mantém as partículas em suspensão (Van Oorschot, 2001).

As gomas têm tido variadas aplicações através dos séculos, incluindo desde adesivo para a mumificação dos faraós até coberturas protetoras de alimentos para os astronautas (Glicksman, 1969). Estes compostos são obtidos de ampla variedade de fontes. Muitos são obtidos de plantas, tais como algas, sementes e exsudatos de árvores: outros são produtos da biossíntese microbiana, e outros, ainda, são produzidos por modificações químicas dos polissacarídeos naturais (Garcia-Cruz, 2001). Estes 
polímeros se dissolvem ou dispersam-se em água para dar espessamento ou efeito de ganho de viscosidade. As gomas também são usadas para efeitos secundários incluindo estabilização da emulsão, suspensão de partículas, controle de cristalização, inibição de sinérese, encapsulação e formação de filmes. Poucas formam gel (Dziezak, 1991).

A goma carragena é um dos agentes formadores de gel mais comuns em sobremesas lácteas. Em misturas para sorvete, a carragena é um componente estabilizante, que evita a separação das fases ou sinérese durante a armazenagem (Garcia-Cruz, 2001). Esta goma é particularmente apropriada para aplicação em sobremesas de leite, pois apresenta inúmeras vantagens (Glicksman, 1983): (1) baixo nível de uso devido à sua alta reatividade com a proteína do leite (especialmente com a k-caseína); (2) ampla variedade de texturas de sobremesas lácteas pode ser obtida de acordo com o tipo e frações de carragena usadas, muitas vezes em combinação com outros hidrocolóides tais como amido e goma locusta; (3) precisam ser aquecidas somente a $70^{\circ} \mathrm{C}$ a fim de dissolver adequadamente; (4) quando tratadas com calor, as carragenas desenvolvem baixa viscosidade e isso facilita o processo (bombeando, transferência rápida de calor); (5) as carragenas não mascaram os sabores.

A viscosidade obtida depende da concentração, da temperatura, da presença de outros sólidos, do tipo de carragena e de seu peso molecular. A viscosidade aumenta exponencialmente com a concentração. Esta conduta é típica de polímeros lineares com grupos carregados e é resultado da maior interação entre cadeias de polímeros quando a concentração aumenta (Lara, 1993).

A goma guar é extraída do endosperma da semente de Cyamopsis tetragonolobus, uma planta anual que pertence à família das leguminosas. Não forma gel, é compatível com outras gomas, amidos, hidrocolóides e agentes gelificantes (naturais e sintéticos). Interage sinergisticamente com a goma xantana resultando em aumento na viscosidade da solução. Quando adicionada em mistura com polissacarídeos geleificantes, agar e carragena, pode aumentar a força do gel e modificar sua estrutura (Dziezak,1991; Sanderson, 1996).

Esta goma produz soluções viscosas com comportamento pseudoplástico em baixas concentrações, isto é, a viscosidade decresce com o cisalhamento e é usada em aplicações nas quais é necessário espessamento, estabilização, controle reológico e de viscosidade, suspensão e formação de corpo, modificação de textura e consistência e retenção de água. Além disso, a goma não é desfavoravelmente afetada pelos baixos valores de $\mathrm{pH}$ e é efetiva em produtos ácidos. Em produtos de laticínios, como queijos processados, fornece textura macia e reduz a sinérese (Sanderson, 1981).
Pela escassez de trabalhos dedicados ao tema, neste trabalho estudaram-se os efeitos do uso de concentrado protéico de soro e de misturas de gomas carragena e guar nas características físico-químicas e sensoriais de sobremesas lácteas achocolatadas cremosas.

\section{MATERIAIS E MÉTODOS}

\section{Preparação das sobremesas}

Na preparação da sobremesa láctea, o concentrado protéico de soro foi usado juntamente com o leite em pó integral, conforme o experimento, totalizando $8,00 \%$ de sólidos lácteos. A carragena foi usada juntamente com a goma guar, conforme o experimento, totalizando $0,30 \%$ de goma adicionada. A quantidade de açúcar foi fixada em $11,50 \%$, a de chocolate em pó em $2,80 \%$, a quantidade de sorbato em $0,08 \%$ em todos os experimentos.

O leite em pó, o concentrado protéico de soro, o açúcar, o chocolate, o sorbato e a mistura de gomas (carragena e guar) foram pesados e misturados na forma seca. A seguir, foram dissolvidos em água a $40{ }^{\circ} \mathrm{C}$ e mantidos sob agitação para a perfeita dissolução dos ingredientes. Esta mistura foi aquecida a $80^{\circ} \mathrm{C}$ para a pasteurização do produto e hidratação das gomas. Em seguida, o produto foi resfriado e distribuído nas embalagens. Posteriormente, o produto foi transferido para um refrigerador à temperatura de $5{ }^{\circ} \mathrm{C}$, aproximadamente. Após 12 horas de refrigeração foram realizadas as análises físico-químicas e sensoriais.

\section{Caracterização físico-química das sobremesas}

O teor de sólidos totais foi determinado pela secagem por 24 horas a $70{ }^{\circ} \mathrm{C}$ em estufa a vácuo, conforme indicado pela APHA (Case, Bradley Jr., Williams, 1985). A determinação do teor de gordura foi feita pelo método de Gerber, conforme recomendado pela APHA (Case, Bradley Jr., Williams, 1985). O teor de proteínas foi calculado através da determinação de nitrogênio pelo método Micro Kjeldahl, segundo AOAC (Richardson, 1990). Para a conversão de nitrogênio em proteínas, multiplicou-se por 6,38. A determinação do teor de cinzas foi feita por incineração em mufla a $550{ }^{\circ} \mathrm{C}$ (Instituto Adolfo Lutz, 1985). As medidas dos valores de $\mathrm{pH}$ foram feitas em potenciômetro digital. Todas as determinações foram feitas em triplicata.

\section{Caracterização sensorial das sobremesas}

Nesta avaliação o provador expressou sua opinião quanto às amostras numa escala numérica de 5 pontos, sendo 5 - ótimo, 4 - bom, 3 - regular, 2 - ruim e 1 -pés- 
simo (Moraes, 1983). Os atributos avaliados foram: (1) aparência - traduzida pelo "conjunto", relativa à primeira impressão causada pelo produto como um todo; (2) consistência - diz respeito ao "corpo" do produto quando consumido; e (3) sabor.

As amostras foram servidas em potes transparentes de plástico, com capacidade para $100 \mathrm{~mL}$, codificados com números aleatórios de três dígitos, sempre duas horas antes ou depois das refeições, no período mais adequado para realização desta avaliação.

\section{Planejamento estatístico dos experimentos}

O efeito das variáveis: conteúdo de concentrado protéico de soro $(1,00 ; 2,00$ e 3,00\%) em substituição ao leite em pó e conteúdo de carragena na mistura carragenaguar $(0,05 ; 0,15$ e $0,25 \%)$ foi estudado sobre as características físico-químicas e sensoriais das sobremesas lácteas achocolatadas, como mostra a Tabela I.

A análise de variância dos resultados das amostras foi realizada a partir do delineamento de blocos casualizados (DBC), com a utilização do teste de Tukey, (contraste entre médias) considerando-se nível de significância $\mathrm{p}<0,05$ (Gomes, 1977), utilizando o programa computacional STAT, desenvolvido por Banzatto e Kronka (1995).

\section{RESULTADOS E DISCUSSÃO}

\section{Caracterização físico-química das sobremesas lácteas achocolatadas cremosas}

Os resultados das análises físico-químicas (gordura, proteínas, cinzas, $\mathrm{pH}$ e sólidos totais) realizadas nas sobre- mesas lácteas achocolatadas preparadas em laboratório, utilizando-se CPS e mistura de gomas, estão contidos na Tabela II.

Os valores de $\mathrm{pH}$ variaram entre 5,77 e 7,15 para as nove formulações, apresentando diferenças significativas entre as amostras, como pode ser observado na Tabela II. $\mathrm{O} \mathrm{pH}$ das sobremesas achocolatadas encontrou-se mais próximo da neutralidade naquelas em que a adição de CPS foi entre 1,00 e $2,00 \%$ e carragena de 0,05 a $0,15 \%$.

Os efeitos do $\mathrm{pH}$ no comportamento da mistura de soluções de proteína-polissacarídeo diferem dependendo da natureza do polissacarídeo, isto é, neutro, carboxilado, ou sulfatado (Syrbe, Bauer, Klostermeyer, 1998). Carragenas são polissacarídeos sulfatados e são capazes de formar complexos com a caseína, mesmo em pH neutro. A incompatibilidade entre proteínas e polissacarídeos aumenta quando o $\mathrm{pH}$ aproxima do ponto isoelétrico (pI) da proteína, em que a tendência de auto-associação das proteínas é alta, e decresce quando o $\mathrm{pH}$ é diferente do $\mathrm{pI}$ da proteína.

Em sistemas contendo caseína-carragena, o $\mathrm{pH}$ tem um efeito tanto na auto-associação da caseína quanto na associação cruzada de caseína-carragena. Coacervação complexa é observada em pHs abaixo de 4,6, que é o pI da caseína e os dois polímeros carregam cargas opostas. Em pH acima de 4,6, ambos os polímeros têm cargas negativas similares em suas macromoléculas (Ould Eleya, Turgeon, 2000).

Os teores de gordura das sobremesas achocolatadas cremosas situam-se entre 1,40 e $3,27 \%$, sendo que as amostras preparadas segundo os experimentos 1, 4 e 7, em cuja formulação há máxima porcentagem de CPS $(3,00 \%)$ e mínima de leite em pó $(5,00 \%)$, foram as que apresentaram os menores valores para esta resposta. Ainda, os

TABELA I - Matriz de ensaios composta pelas variáveis nas unidades codificadas e originais

\begin{tabular}{|c|c|c|c|c|}
\hline \multirow[t]{2}{*}{ Experimentos } & \multicolumn{2}{|c|}{ Níveis das variáveis codificadas } & \multicolumn{2}{|c|}{ Níveis das variáveis originais } \\
\hline & $X_{1}$ & $\mathbf{X}_{2}$ & $\mathrm{~S}(\%)$ & $\mathrm{C}(\%)$ \\
\hline 1 & +1 & -1 & 3,00 & 0,05 \\
\hline 2 & 0 & -1 & 2,00 & 0,05 \\
\hline 3 & -1 & -1 & 1,00 & 0,05 \\
\hline 4 & +1 & 0 & 3,00 & 0,15 \\
\hline 5 & 0 & 0 & 2,00 & 0,15 \\
\hline 6 & -1 & 0 & 1,00 & 0,15 \\
\hline 7 & +1 & +1 & 3,00 & 0,25 \\
\hline 8 & 0 & +1 & 2,00 & 0,25 \\
\hline 9 & -1 & +1 & 1,00 & 0,25 \\
\hline
\end{tabular}

Em que: $\mathrm{X}_{1}=$ níveis codificados da variável $\mathrm{CPS} ; \mathrm{X}_{2}=$ níveis codificados da variável carragena; $\mathrm{S}=$ teor de concentrado protéico de soro $(\%) ; \mathrm{C}=$ teor de carragena $(\%)$. 
teores de gordura situam-se abaixo daqueles encontrados para as sobremesas comerciais, cuja média para a gordura foi de 4,68\% (Janieri, Amaral, Penna, 1999).

A gordura, responsável pela cremosidade e maciez do alimento na boca, também contribui na aparência, palatabilidade e lubrificação dos alimentos, além de aumentar a sensação de saciedade durante as refeições (Akoh, 1998). Entretanto, produtos com baixo conteúdo ou sem gordura, com pouco ou sem açúcar, ou enriquecidos com fibras e outros componentes, têm ganhado popularidade nos últimos anos devido à crescente demanda por produtos de baixas calorias (Giese, 1996).

Os teores de proteínas variaram entre 2,53 e 3,13\%. As amostras que apresentaram maiores valores foram aquelas formuladas com máxima quantidade de CPS e mínima quantidade de leite em pó (experimentos 1, 4 e 7). Entretanto, o Teste de Tukey, mostrou que não houve diferença significativa entre as amostras, exceto entre os experimentos 2 e 7 , cujos valores foram 2,53 e $3,13 \%$, respectivamente. $\mathrm{O}$ conteúdo de proteínas é um dos mais importantes parâmetros responsáveis pela funcionalidade e valor nutricional dos produtos de soro (Banavara, Anupama, Rankin, 2003).

Verificou-se aumento no valor protéico da sobremesa na medida em que se aumentaram as concentrações de CPS. Este resultado é favorável à sobremesa, uma vez que o aumento de ambas variáveis enriquece nutricionalmente o produto. Por isso, para se obter um produto com alto teor protéico, o ideal é utilizar concentração de CPS de 2,40 a $3,00 \%$. Além disso, as proteínas do soro de leite contribuem para baixar o colesterol sanguíneo, oferecendo certa proteção contra doenças cardiovasculares. Algumas pro- teínas do soro têm ação muito importante sobre o sistema imunológico, estimulando a produção de anticorpos, prevenindo infecções e melhorando o estado infeccioso (Matsubara, 2001).

Os teores de cinzas variaram de 0,45 a $0,91 \%$, sendo estes extremos os valores encontrados para os experimentos 8 e 4, respectivamente. Observou-se que o teor de cinzas teve comportamento diretamente proporcional ao teor de CPS, sendo que o aumento de CPS resultou em maior teor de cinzas. Entretanto, este mesmo teor decresceu com o aumento da concentração de carragena.

Não houve diferença significativa entre o teor de sólidos das amostras, pois apesar dos diferentes ingredientes usados, o teor de sólidos totais foi padronizado nas diferentes formulações. Janieri, Amaral e Penna (1999) encontraram 29,72 a 33,27\% de sólidos totais em sobremesas lácteas comerciais, o que demonstra que é possível preparar sobremesas com características físico-químicas adequadas, similares às comerciais, utilizando-se menor conteúdo de sólidos e, conseqüentemente, menos calorias.

As sobremesas preparadas com CPS conforme os experimentos 3 ( $1,00 \%$ de CPS e $0,05 \%$ de carragena) e $6(1,00 \%$ de CPS e $0,15 \%$ de carragena) foram as que demonstraram maior semelhança com as características físico-químicas dos produtos disponíveis no mercado avaliados por Janieri, Amaral e Penna (1999).

\section{Caracterização sensorial das sobremesas lácteas achocolatadas cremosas}

A Tabela III mostra os resultados médios da avaliação sensorial das sobremesas lácteas achocolatadas e os

TABELA II - Caracterização físico-química e resultados do teste de Tukey (contraste entre médias) para pH, gordura, proteínas, cinzas e sólidos totais

\begin{tabular}{|c|c|c|c|c|c|c|c|c|}
\hline Experimento & S (\%) & $\mathrm{C}(\%)$ & pH & $\begin{array}{c}\text { Gordura } \\
(\%)\end{array}$ & $\begin{array}{c}\text { Proteínas } \\
(\%)\end{array}$ & $\begin{array}{c}\text { Cinzas } \\
(\%)\end{array}$ & $\begin{array}{c}\text { Sólidos } \\
\text { Totais }(\%)\end{array}$ & $\begin{array}{c}\text { Calorias } \\
\text { por } 100 \mathrm{~g}\end{array}$ \\
\hline 1 & 3,00 & 0,05 & $6,92^{\mathrm{f}}$ & $1,40^{\mathrm{d}}$ & $2,94^{\mathrm{ab}}$ & $0,83^{\mathrm{a}}$ & $23,85^{\mathrm{ab}}$ & 99,08 \\
\hline 2 & 2,00 & 0,05 & $7,15^{\mathrm{a}}$ & $2,00^{\mathrm{bcd}}$ & $2,53^{\mathrm{b}}$ & $0,73^{\mathrm{ab}}$ & $23,69^{a b}$ & 101,84 \\
\hline 3 & 1,00 & 0,05 & $7,09^{\mathrm{b}}$ & $3,27^{\mathrm{a}}$ & $2,60^{\mathrm{ab}}$ & $0,48^{\mathrm{d}}$ & $23,54^{b}$ & 108,59 \\
\hline 4 & 3,00 & 0,15 & $6,96^{c}$ & $1,40^{\mathrm{d}}$ & $2,87^{\mathrm{ab}}$ & $0,91^{\mathrm{a}}$ & $23,65^{\mathrm{ab}}$ & 97,96 \\
\hline 5 & 2,00 & 0,15 & $6,94^{\mathrm{e}}$ & $2,00^{\mathrm{bcd}}$ & $2,90^{\mathrm{ab}}$ & $0,72^{\mathrm{abc}}$ & $23,32^{\mathrm{b}}$ & 100,40 \\
\hline 6 & 1,00 & 0,15 & $6,95^{\mathrm{d}}$ & $3,07^{\mathrm{a}}$ & $2,89^{\mathrm{ab}}$ & $0,53^{\mathrm{cd}}$ & $23,72^{\mathrm{ab}}$ & 108,11 \\
\hline 7 & 3,00 & 0,25 & $5,90^{\mathrm{h}}$ & $1,80^{\mathrm{cd}}$ & $3,13^{\mathrm{a}}$ & $0,47^{\mathrm{d}}$ & $23,96^{\mathrm{ab}}$ & 102,96 \\
\hline 8 & 2,00 & 0,25 & $6,91^{\mathrm{g}}$ & $2,80^{\mathrm{abc}}$ & $2,87^{\mathrm{ab}}$ & $0,45^{\mathrm{d}}$ & $23,71^{\mathrm{ab}}$ & 107,04 \\
\hline 9 & 1,00 & 0,25 & $5,77^{\mathrm{i}}$ & $3,00^{\mathrm{ab}}$ & $2,88^{\mathrm{ab}}$ & $0,58^{\mathrm{bcd}}$ & $24,53^{\mathrm{a}}$ & 110,80 \\
\hline
\end{tabular}

abcd - letras iguais indicam que não há diferença significativa entre as amostras; comparação feita apenas para a mesma coluna. $\mathrm{p}=0,05$. Em que: $\mathrm{S}=$ Teor de concentrado protéico de soro (\%), $\mathrm{C}=$ Teor de carragena (\%). 
TABELA III - Caracterização sensorial das sobremesas lácteas achocolatadas e resultados do teste de (contraste entre médias) para os atributos aparência, consistência e sabor

\begin{tabular}{cccccc}
\hline Experimentos & $\mathbf{S}(\%)$ & $\mathbf{C}(\%)$ & Aparência(\%) & Consistência(\%) & Sabor(\%) \\
\hline 1 & 3,00 & 0,05 & $3,87^{\mathrm{a}}$ & $3,43^{\mathrm{ab}}$ & $4,23^{\mathrm{ab}}$ \\
2 & 2,00 & 0,05 & $4,03^{\mathrm{a}}$ & $2,97^{\mathrm{b}}$ & $4,20^{\mathrm{ab}}$ \\
3 & 1,00 & 0,05 & $4,03^{\mathrm{a}}$ & $3,37^{\mathrm{ab}}$ & $4,30^{\mathrm{a}}$ \\
4 & 3,00 & 0,15 & $3,80^{\mathrm{a}}$ & $3,60^{\mathrm{a}}$ & $4,00^{\mathrm{abc}}$ \\
5 & 2,00 & 0,15 & $3,63^{\mathrm{a}}$ & $3,23^{\mathrm{ab}}$ & $3,57^{\mathrm{c}}$ \\
6 & 1,00 & 0,15 & $3,80^{\mathrm{a}}$ & $3,47^{\mathrm{ab}}$ & $3,93^{\mathrm{abc}}$ \\
7 & 3,00 & 0,25 & $3,67^{\mathrm{a}}$ & $3,47^{\mathrm{ab}}$ & $3,50^{\mathrm{c}}$ \\
8 & 2,00 & 0,25 & $3,67^{\mathrm{a}}$ & $3,60^{\mathrm{a}}$ & $3,63^{\mathrm{bc}}$ \\
9 & 1,00 & 0,25 & $3,80^{\mathrm{a}}$ & $3,40^{\mathrm{ab}}$ & $3,47^{\mathrm{c}}$ \\
\hline
\end{tabular}

abcd - letras iguais indicam que não há diferença significativa entre as amostras; comparação feita apenas para a mesma coluna. $\mathrm{p}=0,05$. Em que: $\mathrm{S}=$ Teor de concentrado protéico de soro (\%), $\mathrm{C}=$ Teor de carragena (\%)

resultados do teste de Tukey para os parâmetros aparência, consistência e sabor, respectivamente, obtidos na avaliação por 30 provadores não treinados.

Para o parâmetro aparência, as sobremesas dos experimentos 2 e 3 obtiveram a maior média $(4,03)$. A sobremesa láctea obtida a partir do experimento $5(2,00 \%$ de CPS e $0,15 \%$ de carragena) foi a que apresentou o menor valor para este atributo $(3,63)$, uma vez que a combinação entre conteúdo de soro e carragena resultou em um produto com formação de grumos, conferindo visual menos atrativo. De qualquer forma, sua qualidade foi considerada acima de regular (nota 3 ) pelos provadores, sem diferença significativa com as demais amostras.

A adição de polissacarídeos ao leite pode resultar na separação de fases enriquecidas em polissacarídeos e fases enriquecidas em caseína se a concentração de polissacarídeos excede a certas concentrações (Tuinier, Tem Grotenhuis, de Kruif, 2000). Por esta razão, concentrações de gomas e caseína precisam ser otimizadas para permitir a máxima interação entre o hidrocolóide e a proteína. Se a concentração goma-proteína não é otimizada, então interações hidrocolóide-hidrocolóide ou proteínaproteína podem predominar, afetando portanto a reatividade no leite.

A reatividade de gomas com proteínas lácteas é influenciada pelo tipo de tratamento térmico (batelada ou contínuo), tipo de proteína do leite (leite em pó reconstituído ou concentrado protéico de soro) e tipo de goma (carragena, guar e xantana). A goma guar exibiu reatividade com concentrado protéico de soro em todas as concentrações testadas $(0,05,0,1$ e $0,2 \% \mathrm{p} / \mathrm{v})$ no tratamento contínuo; o mesmo não aconteceu com as demais gomas e com o leite em pó. Estes resultados sugerem que a concentração da goma e a fonte de proteína são parâmetros importantes para otimizar a propriedade das gomas de reagir com o leite (Schmidt, Smith, 1992).

Para o parâmetro consistência, as sobremesas dos experimentos 4 e 8, em cujas formulações foram usados $3,00 \%$ de CPS e $0,15 \%$ de carragena, e $2,00 \%$ de CPS e $0,25 \%$ de carragena, respectivamente, obtiveram a maior média $(3,60)$ considerada regular pelos provadores, diferindo significativamente somente daquela obtida no experimento $2(2,00 \%$ de CPS e $0,05 \%$ de carragena), que apresentou menor valor para este atributo $(2,97)$.

Para o atributo sabor, a sobremesa do experimento 3 , em cuja formulação foram usados $1,00 \%$ de CPS e $0,05 \%$ de carragena, obteve a maior média $(4,30)$, diferindo significativamente das amostras dos experimentos 5,7 e 9 , as quais foram preparadas com $2,00 \%$ de CPS e $0,15 \%$ de carragena; $3,00 \%$ de CPS e 0,25 de carragena e $1,00 \%$ de CPS e $0,25 \%$ de carragena, respectivamente, cujas notas relacionadas ao atributo sabor foram as menores, mas acima do valor considerado de qualidade regular.

Resultados promissores do uso de CPS em sobremesas lácteas e em iogurtes foram relatados na literatura. O CPS foi o mais adequado entre os testados para substituir a gordura em sobremesas lácteas congeladas ("frozen yogurt"), demonstrando que é possível elaborar uma sobremesa láctea nutritiva, com substitutos de gordura e com boa aceitabilidade sensorial (Broisler, Mariusso, Penna, 2002). Iogurtes probióticos de baixas calorias foram elaborados com CPS 35\% e CPS $80 \%$ sem prejuízos nas características físico-químicas e microbiológicas (Castro et al., 2002).

A influência das variáveis sobre o sabor demonstra que as sobremesas lácteas mais saborosas, cujas notas foram acima 4 (boa qualidade), consistiram naquelas preparadas com CPS variando de 1,00 até $3,00 \%$ e carragena 
variando de 0,05 até $0,15 \%$. Isto mostra, também, que o teor de CPS sozinho não tem grande influência sobre o sabor, uma vez que as amostras que obtiveram as menores notas para este atributo foram preparadas com quantidades diferentes de CPS.

Assim, fazendo-se análise geral dos três atributos julgados pelos provadores, a sobremesa láctea achocolatada preparada com CPS, conforme o experimento $3(1,00 \%$ de CPS e $0,05 \%$ de carragena), foi considerada pelos provadores a melhor dentre todas as testadas. Por outro lado, a sobremesa láctea do experimento 5 (2,00\% de CPS e $0,15 \%$ de carragena) recebeu a menor nota na avaliação sensorial e foi considerada a pior pelos provadores.

\section{CONCLUSÃO}

As sobremesas lácteas achocolatadas preparadas em laboratório apresentaram, em geral, menores teores de gordura e de sólidos totais do que as sobremesas lácteas disponíveis no comércio. As sobremesas contendo concentrado protéico de soro apresentam redução do valor calórico, atendendo às expectativas de pessoas que buscam constantemente melhorias na saúde e dieta pouco calórica. Além disso, a presença do CPS promove aumento no teor protéico, resultando, conseqüentemente, em maior valor nutritivo, quando comparadas às sobremesas disponíveis no mercado.

As sobremesas preparadas com CPS conforme os experimentos 3 ( $1,00 \%$ de CPS e $0,05 \%$ de carragena) e $6(1,00 \%$ de CPS e $0,15 \%$ de carragena) foram as que demonstraram maior semelhança com as características físico-químicas dos produtos disponíveis no mercado.

Os resultados obtidos da análise sensorial mostram que é viável fazer a substituição parcial do leite em pó por concentrado protéico de soro na formulação de sobremesa láctea achocolatada com boa aceitabilidade sensorial. As sobremesas lácteas preparadas com CPS segundo o experimento 3 ( $1,00 \%$ de CPS e $0,05 \%$ de carragena) foi considerada a melhor pelos provadores, tendo apresentado maiores notas nos atributos estudados.

\section{ABSTRACT}

\section{Technological characterization of creamy chocola- te dairy desserts prepared with whey protein concentrate and a mixture of carrageenan and guar gum}

The consumption of dairy desserts has boomed in the last few decades, due to the technological progress in the development of ingredients and processes. In this study the physicochemical and sensory characterization of creamy chocolate dairy desserts were carried out. Whey powder concentrate - WPC (3.0; 2.0 and $1.0 \%$ ) was used with whole milk powder (5.0; 6.0 and $7.0 \%)$, carrageenan (0.05; 0.15 and $0.25 \%)$, guar gum $(0.25 ; 0.15$ and $0.05 \%)$, cocoa powder $(2.8 \%)$, sugar (11.5\%) and potassium sorbate (0.08\%), according to the trial. The results showed that it is possible to use WPC, replacing whole milk powder, and therefore creating a product with low fat and total solids, and high protein content. The final product presented better nutritional quality, besides reduced caloric value, which favors the consumption by people concerned with health. The experimental dairy dessert prepared with $1.00 \%$ WPC, $7.00 \%$ whole milk powder, $0.05 \%$ carrageenan and $0.25 \%$ guar gum was considered the best by the panellists, with acceptability higher than value 4 (good).

UNITERMS: Dairy desserts. Whey protein concentrate. Carrageenan. Guar gum. Dairy products.

\section{REFERÊNCIAS BIBLIOGRÁFICAS}

AKOH, C.C. Fat replacers. Food Technol., v. 52, n. 3, p. 4753, 1998.

ALVES, R.M.V.; GARCIA, E.E.C.; DANTAS, S.T.; PADULA, M. Embalagem: qualidade e vida de prateleira. Leite e Derivados, v. 3, n. 14, p.26-31, 1994.

BANAVARA, D.S.; ANUPAMA, D.; RANKIN, S.A. Studies on physicochemical and functional properties of commercial sweet whey powders. J. Dairy Sci., v. 86, n. 12, p. 3866-3875, 2003.

BANZATTO, D.A.; KRONKA, S.D. Experimentação Agrícola. 3.ed. Jaboticabal: FUNESP, 1995. 247 p.

BROISLER, P.O.; MARIUSSO, A.C.B.; PENNA, A.L.B. Uso de substitutos de gordura no "frozen yogurt" probiótico. Rev. Inst. Laticínios Cândido Tostes, v. 57, n. 327, p. 140-142, 2002.

CASE, R.A.; BRADLEY JUNIOR, R.L.; WILLIAMS, R.R. Chemical and physical methods. In: American Public Health Association - Standard methods for the examination of dairy products. 15.ed. Washington: APHA.1985. p. 327-404. 
CASTRO, L.P.; PINHEIRO, M.V.S.; HOFFMANN, F.L.; PENNA, A.L.B. Influência de substitutos de gordura nas características do iogurte probiótico. Rev. Inst. Laticínios Cândido Tostes, v. 57, n. 327, p. 133-136, 2002.

DZIEZAK, J.D. A focus on gums. Food Technol., v. 45, n. 3, p. 117-120, 122-124, 126, 128, 130-132, 1991.

FREITAS, L.C.G. Leites geleificados. Juiz de Fora: EPAMIG, [s.d.]. 13 p.

GARCIA-CRUZ, C.H. Uso de hidrocolóides em alimentos: revisão. Hig. Aliment., v. 15, p. 19-28, 2001.

GIESE, J. Fat and fat replacers: balancing the health benefits . Food Technol., v. 50, n. 9, p. 76-81, 1996.

GLICKSMAN, M. Gum technology in the food industry. San Diego: Academic Press, 1969. 590p.

GLICKSMAN, M. The role of hydrocolloids in food processing - cause and effect. In: Gums and stabilisers for the food industry. Oxford: Pergamon Press, 1983. v. 2, p. 297-320.

GOMES, F.P. Curso de estatística experimental. 7 ed. São Paulo: Nobel, 1977.466 p.

INSTITUTO ADOLFO LUTZ. Normas analiticas do Instituto Adolfo Lutz. 2.ed. São Paulo, 1985. v. 1, 371p.

JANIERI, C.; AMARAL, F.F.; PENNA, A.L.B. Análises físico-químicas de sobremesas lácteas cremosas. In: COLÓQUIO DE INCENTIVO À PESQUISA, 26., São José do Rio Preto, 1999. Livro de Resumos. São José do Rio Preto: IBILCE/UNESP, 1999. [resumo A-2].

LAGRANGE, V.; DALLAS, P. Inovação de produto com concentrados de proteína de soro de leite dos USA. Bol. Soc. Bras. Ciênc. Tecnol. Aliment., v. 31, n. 1, p. 17-21, 1997.

LARA, S.R. Tecnologia geral de aplicação de carragena. In: SIMPÓSIO SOBRE HIDROCOLÓIDES, Campinas, 1991. Anais. Campinas: ITAL, 1993. p.22-50

LIANG, B.; HARTEL, R. W. Effects of milk powder in milk chocolate. J. Dairy Sci., v. 87, n. 1, p. 20-31, 2004.
MATSUBARA, S. Alimentos funcionais. Indústria de Laticínios, v. 6, n. 34, p. 10-18, 2001.

MORAES, M.A.C. Métodos para avaliação sensorial dos alimentos. Campinas: Ed. UNICAMP, 1983. 73 p.

NUNES, M.C.; MURATA, L.T.F.; ALCÂNTARA, M.R.S.; GERMANO, M.I.S.; GERMANO, P.M.L. Avaliação das sobremesas lácteas: características que podem comprometer a garantia de qualidade. Hig. Aliment., v. 12, n 58, p. 41-48, 1998.

OULD ELEYA, M.M.; TURGEON, S.L. The effects of $\mathrm{pH}$ on the rheology of $\beta$-lactoglobulin/ $/$-carrageenan mixed gels. Food Hydrocolloids, v. 14, n. 3, p. 245-251, 2000.

RICHARDSON, G.H. Dairy products. In: ASSOCIATION OF OFFICIAL ANALYTICAL CHEMISTS. Official methods of analysis. 15 ed. Arlington: AOAC, 1990. p. $802-852$.

SANDERSON, G.R. Gums and their use in food systems. Food Technol., v. 50, n. 3, p. 81-84, 1996.

SANDERSON, G.R. Polysaccharides in foods. Food Technol., v. 35, n. 7, p. 50-57, 83, 1981.

SCHMIDT, K.A.; SMITH, D.E. Milk reativity of gum and milk protein solutions. J. Dairy Sci., v. 75, n. 12, p. 3290$3295,1992$.

SYRBE, A.; BAUER, W.J.; KLOSTERMEYER, H. Polymer science concepts in dairy systems - An overview of milk protein and food hydrocolloid interation. Int. Dairy J., v. 8, n. 3, p. 179-193, 1998.

TUINIER, R.; TEN GROTENHUIS, E.; KRUIF, C. G. The effect of depolymerised guar gum on the stability of skim milk. Food Hydrocolloids, v. 14, n. 1, p. 1-7, 2000.

USDEC - United States Dairy Export Council. Manual de referência para produtos de soro dos EUA. Arlington: USDEC, 1997. 135 p.

VAN OORSCHOT, N. Perfeição em matéria de sobremesas e leites achocolatados. Leite e Derivados, v. 10, n. 58, p. 28-31, 2001.

Recebido para publicação em 15 de abril de 2004. Aceito para publicação em 30 de agosto de 2004. 